\title{
STUDY OF GLUCOSE 6-PHOSPHATE DEHYDROGENASE (G6PD) DEFICIENCY IN JAUNDICED NEONATES OF A TERTIARY CARE CENTRE OF NORTH-EAST INDIA
}

\author{
Aukifa Khamim Sabibahul Islam¹, Reeta Bora², Sutharson Ramasamy33, Manjit Boruah ${ }^{4}$ \\ ${ }^{1}$ Assistant Professor, Department of Paediatrics, Assam Medical College and Hospital. \\ ${ }^{2}$ Associate Professor, Department of Paediatrics, Assam Medical College and Hospital. \\ 3 Post Graduate Student, Department of Paediatrics, Assam Medical College and Hospital. \\ 4 Demonstrator, Department of Community Medicine, Assam Medical College and Hospital.
}

\begin{tabular}{l} 
ABSTRACT \\
\hline BACKGROUND \\
Glucose-6-Phosphate Dehydrogenase (G6PD) is an enzyme essential for basic cellular functions including protection of red cell \\
proteins from oxidative damage. Glucose-6-Phosphate Dehydrogenase (G6PD) deficiency is the commonest red cell enzyme \\
abnormality associated with haemolysis leading to Neonatal Jaundice (NNJ). It is a genetically inherited X-linked abnormality.
\end{tabular}

\section{AIMS}

To find out incidence of G6PD deficiency amongst jaundiced patients and relation between G6PD deficiency and sex, peak level of Total Serum Bilirubin (TSB), significant hyperbilirubinemia, duration of phototherapy and need for exchange transfusion.

\section{SETTINGS AND DESIGN}

Hospital based retrospective study.

\section{METHODS AND MATERIALS}

This retrospective study was carried out among 1224 jaundiced neonates needing phototherapy admitted in the Neonatology Unit of Dept. of Paediatrics (March 2015 to October 2015), Assam Medical College and Hospital (AMCH), Dibrugarh, Assam.

\section{STATISTICAL ANALYSIS USED}

Data were entered in SPSS (Software package for statistical analysis), version 16 and analysed using Chi-Square test and Mann Whitney U test.

\section{RESULTS}

A total of 2574 neonates were admitted during the 8 months period, of which 1224 had NNJ (47.5\%). Of these 77 (5.07\%) babies were G6PD deficient. Male $(n=53)$ to female $(n=24)$ ratio was 2:1. The commonest age at presentation was $2^{\text {nd }}$ to $4^{\text {th }}$ days in both G6PD deficient and G6PD normal neonates. Mean peak-TSB level in G6PD deficient cases $(20.03 \pm 5.30 \mathrm{mg} / \mathrm{dL}) \mathrm{was}$ significantly higher than G6PD normal cases $(16.67 \pm 3.93 \mathrm{mg} / \mathrm{dL}) ; 45 \%$ of G6PD deficient neonates developed significant hyperbilirubinemia (Indirect bilirubin more than $20 \mathrm{mg} \%$ ) and required Double Volume Exchange Transfusion (DVET). Mean duration of phototherapy in G6PD deficient NNJ babies is $2.5 \pm 1.2$ days, which is significantly higher $(\mathrm{p}<0.05)$ when compared to G6PD normal NNJ babies where it is $2 \pm 1.1$ days. In babies with significant hyperbilirubinemia, it is seen that there is significant difference $(p<0.001)$ between G6PD deficient and G6PD normal babies. There was significant difference in requirement of DVET between G6PD deficient and G6PD normal NNJ cases $(\mathrm{P}<0.001)$.

\section{CONCLUSION}

In this region of the country, G6PD is an important cause for severe neonatal jaundice requiring exchange transfusion. Early detection of this enzyme deficiency by universal screening and close surveillance of the affected newborns is important in reducing the risk of severe hyperbilirubinemia.

\section{KEYWORDS}

Enzyme, Glucose-6-phosphate Dehydrogenase, Neonatal Hyperbilirubinemia, Phototherapy, Double Volume Exchange Transfusion.

HOW TO CITE THIS ARTICLE: Islam AKS, Bora R, Ramasamy S, et al. Study of glucose 6-phosphate dehydrogenase (G6PD) deficiency in jaundiced neonates of a tertiary care centre of north-east India. J. Evolution Med. Dent. Sci. 2016;5(38):2271-2275, DOI: $10.14260 /$ jemds/2016/528

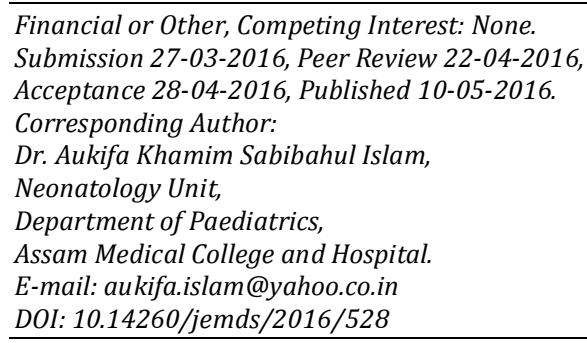

\section{INTRODUCTION}

Hyperbilirubinemia is the most common morbidity in neonatal period for which neonate needs medical attention. Neonatal jaundice is a very common condition worldwide occurring in up to $60 \%$ of term and $80 \%$ of preterm newborns in the first week of life with 5 to $10 \%$ needing intervention for treatment of hyperbilirubinemia. ${ }^{1}$ High bilirubin level may be toxic to developing central nervous system and may cause neurological impairment even in term newborns. 
Significant neonatal unconjugated hyperbilirubinemia can be caused by prematurity, ABO and RH incompatibility, G6PD deficiency, minor blood group incompatibility or idiopathic aetiology, of which $\mathrm{ABO}$ incompatibility is most common aetiology followed by the other causes. One of the most important cause of significant jaundice is G6PD deficiency. Approximately $7.5 \%$ of world population carry one or two genes for G6PD deficiency and $2.9 \%$ are genetically deficient for the enzyme. ${ }^{2}$ The inherited deficiency of this enzyme may manifest as congenital non-spherocytic haemolytic anaemia, drug induced haemolytic anaemia or haemolytic disease of new born.

Glucose 6-phosphate dehydrogenase is essential for the stability of red blood cells. ${ }^{3}$ Most of the mutations are single base substitutions. ${ }^{4}$ The gene for G6PD is on long arm of the X chromosome at position q28.5 One of the most extraordinary features of G6PD gene is the many mutations that affect this enzyme in humans. More than 300 genetic variants of G6PD have been described in association with a wide spectrum of haemolytic anaemia. Many reports have emphasized on the risk of kernicterus in G6PD deficient neonates and thus more aggressive treatment is indicated. $6,7,8$

G6PD deficiency was initially described in 1956.4 In India, G6PD deficiency was first reported in 1963 by Baxi et al. ${ }^{9}$ and the prevalence rate varied from 0 to $27 \%$ in different caste, ethnic and linguistic groups. ${ }^{10}$ So far researchers have conducted various studies in this subject. But still there are limited studies from this part of Assam.

The retrospective study for 8 months (March 2015 to October 2015) in Assam Medical College and Hospital, Dibrugarh, was done to find out the relation between G6PD deficiency and sex, peak level of TSB, significant hyperbilirubinemia, duration of phototherapy, requirement of exchange transfusion.

\section{AIMS}

1. To find out incidence of G6PD deficiency amongst jaundiced patients.

2. To find relation between G6PD deficiency and sex, peak level of Total Serum Bilirubin (TSB), significant hyperbilirubinemia, duration of phototherapy and need for exchange transfusion.

\section{METHODS AND MATERIALS}

The study was a retrospective study done for a period of 8 months (March 2015 to October 2015) in the Neonatology Unit of Dept. of Paediatrics, Assam Medical College and Hospital (AMCH), Dibrugarh, Assam.

\section{SELECTION OF CASES}

\section{Inclusion Criteria}

1. All neonates (Both inborn and outborn) presenting with hyperbilirubinemia admitted in neonatal unit for phototherapy.

\section{Exclusion Criteria}

1. Neonates with conjugated hyperbilirubinemia.

2. Neonates with sepsis, polycythemia.

\section{Method}

Retrospectively data obtained from neonatal unit admission register, phototherapy register and computer entered data was analysed for aetiology of unconjugated hyperbilirubinemia with special reference to G6PD deficiency, sex of neonate, day of onset of NNJ, peak level of TSB, significant hyperbilirubinemia, duration of double surface phototherapy, requirement of DVET were analysed.

a. Data regarding patient demographics: - Gestational age, religion, gender, ethnicity and order of birth.

b. Investigations: - Daily total serum bilirubin, G6PD enzyme level, Mother's Blood Group (MBG), Baby's Blood Group (BBG) and Direct Coomb's Test (DCT).

c. Data related to jaundice: - Age at onset of jaundice, duration of Double Surface Phototherapy (DSPT), DVETdone or not, no. of DVET, day of DVET, NNJ passive by which day, final outcome-improved or died were collected.

For erythrocyte G6PD determination, blood was collected in a $4 \mathrm{~mL}$ tube containing EDTA as anticoagulant. Enzyme activity was measured quantitatively by Kinetic method using 'G-SIX Kit' in Advanced Clinical Biochemistry Laboratory, AMCH. Any neonate with a value $<6.4 \mathrm{u} / \mathrm{g} \mathrm{Hb}$ was considered G6PD deficient.

\section{Management Protocol for NNJ Cases in SNCU, Assam Medical College}

After identifying clinical jaundice in the newborn, their TSB level is noted following which admission for DSPT or DVET is determined as per neonatal hyperbilirubinemia practice guidelines from AAP-2004 (American Academy of Paediatrics) for newborns - 35 weeks and above and from NICE (National Institute for Health and Care Excellence) guidelines for preterm newborns less than 35 weeks. Further investigations are done as per guidelines (G6PD enzyme level, MBG, BBG and DCT)

\section{Statistical Analysis Used}

Data were entered in a software called SPSS (Software package for statistical analysis), version 16. Data were analysed using Chi-Square test and Mann Whitney U test.

\section{RESULTS}

A total of 2574 (Inborn-1620, outborn-954) neonates were admitted during the 8 months' period. Of these 1224 (Inborn1006, outborn-218) had NNJ (47.5\%). Of the NNJ babies, 77 $(5.07 \%)$ were G6PD deficient and it constituted $2.9 \%$ of total admissions. Of total NNJ cases 568 (49.5\%) were males and $579(50.4 \%)$ were females. Of G6PD deficient neonates, 53 $(68.4 \%)$ were males and $24(31.5 \%)$ were females with a ratio of $\mathrm{M}: \mathrm{F}=2: 1$. The commonest age at presentation was $2^{\text {nd }}$ to $4^{\text {th }}$ days in both G6PD deficient and G6PD normal neonates. Mean Peak - TSB level in G6PD deficient cases $(20.03 \pm 5.30$ $\mathrm{mg} / \mathrm{dL})$ was significantly higher $(\mathrm{p}<0.001)$ than G6PD normal cases $(16.67 \pm 3.93 \mathrm{mg} / \mathrm{dL}) ; 45 \%$ of G6PD deficient neonates developed significant hyperbilirubinemia (Indirect bilirubin more than $20 \mathrm{mg} \%$ ) and required Double Volume Exchange Transfusion (DVET). Mean duration of phototherapy in G6PD deficient NNJ babies is $2.5 \pm 1.2$ days, which is significantly higher $(\mathrm{p}<0.05)$ when compared to G6PD normal NNJ babies where it is $2 \pm 1.1$ days. In babies with significant hyperbilirubinemia, it is seen that there is significant difference $(\mathrm{p}<0.001)$ between G6PD deficient and G6PD normal babies. 
There was significant difference in requirement of DVET between G6PD deficient and G6PD normal NNJ cases $(\mathrm{P}<0.001)$. Only 2 babies developed kernicterus (One in each group).

\begin{tabular}{|c|c|c|}
\hline Aetiology & $\begin{array}{c}\text { No. of Cases } \\
\text { N }\end{array}$ & $\begin{array}{c}\text { Percentage } \\
\text { (\%) }\end{array}$ \\
\hline Prematurity & 116 & 9.4 \\
\hline Rhesus disease & 39 & 3.1 \\
\hline ABO incompatibility & 168 & 13.7 \\
\hline G6PD deficiency & 62 & 5.06 \\
\hline Idiopathic aetiology & 791 & 64.62 \\
\hline $\begin{array}{c}\text { ABO setting/G6PD } \\
\text { deficiency }\end{array}$ & 5 & 0.40 \\
\hline ABO setting/Rh setting & 2 & 0.16 \\
\hline AB0 setting/Prematurity & 26 & 2.1 \\
\hline Prematurity/Rh setting & 5 & 0.40 \\
\hline $\begin{array}{c}\text { Prematurity/G6PD } \\
\text { deficiency }\end{array}$ & 8 & 0.65 \\
\hline $\begin{array}{c}\text { Rh setting/G6PD } \\
\text { Deficiency }\end{array}$ & 1 & 0.08 \\
\hline $\begin{array}{c}\text { ABO } \\
\text { incompatability/PM/G6PD } \\
\text { deficiency }\end{array}$ & 1 & 0.08 \\
\hline \multicolumn{2}{|c|}{ Table 1: Aetiology of the Unconjugated } \\
\hline \multicolumn{2}{|c|}{ Hyperbilirubinemia } \\
\hline
\end{tabular}

\begin{tabular}{|c|c|c|c|c|c|}
\hline \multirow{3}{*}{ Sex } & \multicolumn{2}{|c|}{ No. of Cases } & \multicolumn{2}{c|}{ Percentage (\%) } & \multirow{2}{*}{ P value } \\
\cline { 2 - 4 } & $\begin{array}{c}\text { G6PD- } \\
\text { Deficient }\end{array}$ & $\begin{array}{c}\text { G6PD- } \\
\text { Normal }\end{array}$ & $\begin{array}{c}\text { G6PD- } \\
\text { Deficient }\end{array}$ & $\begin{array}{c}\text { G6PD- } \\
\text { Normal }\end{array}$ & \\
\hline Male & 53 & 568 & 68.4 & 49.5 & \\
\hline Female & 24 & 579 & 31.5 & 50.4 & $\mathrm{P}=0.001$ \\
\hline Total & $\mathbf{7 7}$ & $\mathbf{1 1 4 7}$ & $\mathbf{1 0 0}$ & $\mathbf{1 0 0}$ & \\
\hline \multicolumn{6}{|c|}{ Table 2: Sex Wise Distribution in G6PD } \\
Deficient vs. G6PD Normal NNJ Babies \\
\hline
\end{tabular}

\begin{tabular}{|c|c|c|c|}
\hline Community & $\begin{array}{c}\text { Total No. of } \\
\text { Cases }\end{array}$ & $\begin{array}{c}\text { G6PD Deficient } \\
\text { NNJ Babies }\end{array}$ & $\begin{array}{c}\text { G6PD } \\
\text { Normal } \\
\text { NNJ } \\
\text { Babies }\end{array}$ \\
\hline Tribal & $122(9.9 \%)$ & $12(9.8 \%)$ & $\begin{array}{c}110 \\
(90.1 \%)\end{array}$ \\
\hline Tea-Garden & $\begin{array}{c}182 \\
(14.8 \%)\end{array}$ & $14(7.6 \%)$ & $\begin{array}{c}168 \\
(92.3 \%)\end{array}$ \\
\hline Others & $\begin{array}{c}920 \\
(75.1 \%)\end{array}$ & $51(5.5 \%)$ & $\begin{array}{c}869 \\
(94.4 \%)\end{array}$ \\
\hline Total & $\mathbf{1 2 2 4}$ & $\mathbf{7 7}$ & $\mathbf{1 1 4 7}$ \\
\hline Table 3: Community-Wise Distribution of NNJ Babies \\
\hline
\end{tabular}

\begin{tabular}{|c|c|c|c|c|c|}
\hline \multirow{2}{*}{ Age at Presentation } & \multicolumn{2}{|c|}{ No. of Cases } & \multicolumn{2}{c|}{ Percentage (\%) } & P value \\
\cline { 2 - 6 } & G6PD-Deficient & G6PD-Normal & G6PD-Deficient & G6PD-Normal & \\
\hline Upto 24 years of age & 3 & 53 & 3.8 & 7.6 & 76.3 \\
\hline $2^{\text {nd }}$ day to 4th day of age & 57 & 876 & 74 & 19.0 & P $>0.05$ \\
\hline After 4th day of age & 17 & 218 & 22.07 & 100 & \\
\hline TOTAL & 77 & 1147 & 100 & \\
\hline
\end{tabular}

\begin{tabular}{|c|c|c|c|c|c|c|}
\hline \multirow{2}{*}{ Grade } & & \multicolumn{2}{|c|}{ No. of cases } & \multicolumn{2}{|c|}{ Percentage (\%) } & \multirow[t]{2}{*}{ P value } \\
\hline & & G6PD-Deficient & G6PD-Normal & G6PD-Deficient & G6PD-Normal & \\
\hline Mild-to-moderate & $<20 \mathrm{mg} \%$ & 42 & 994 & 54.5 & 86.6 & $\mathrm{P}<0.001$ \\
\hline Severe & $>20 \mathrm{mg} \%$ & 35 & 153 & 45.5 & 13.3 & \\
\hline
\end{tabular}

\begin{tabular}{|c|c|c|c|c|c|}
\hline \multirow{2}{*}{ Duration of Phototherapy } & \multicolumn{2}{|c|}{ No. of Cases } & \multicolumn{2}{c|}{ Percentage (\%) } & P value \\
\cline { 2 - 6 } & G6PD-Deficient & G6PD-Normal & G6PD-Deficient & G6PD-Normal & 74.1 \\
\hline$<48$ hours & 42 & 851 & 54.5 & 24.4 & P $<0.05$ \\
\hline 3 to 5 days & 31 & 280 & 40.25 & 1.39 & \\
\hline$>5$ days & 4 & 16 & 5.1 & 3 \\
\hline
\end{tabular}

\begin{tabular}{|c|c|c|c|c|c|}
\hline \multirow{2}{*}{} & \multicolumn{2}{|c|}{ No. of Cases } & \multicolumn{2}{c|}{ Percentage (\%) } & P value \\
\cline { 2 - 6 } & G6PD-Deficient & G6PD-Normal & G6PD-Deficient & G6PD-Normal & P $<0.001$ \\
\hline DVET & 35 & 153 & 45.45 & 13.3 & \\
\hline \multicolumn{4}{|c|}{ Table 7: Requirement of DVET in G6PD-Deficient vs. G6PD-Normal Babies } \\
\hline
\end{tabular}

\section{DISCUSSION}

In this study, almost half $(47.5 \%)$ of the total admission in Newborn Unit are due to neonatal jaundice. This fact is supported by International and local studies, which reflects that neonatal jaundice is an important cause of neonatal nursery admission. An incidence of $54 \%$ in a study in India. ${ }^{11}$ $36.2 \%$ at NICU of Rehman Medical College, Peshawar, Pakistan. ${ }^{12}$ were found.
In our study, $5.07 \%$ of jaundiced babies were found to be G6PD deficient. This incidence varies worldwide according to ethnic variations. Indian population is diverse and comprises of numerous caste and tribal groups, each with characteristic physical and genetic traits. A higher incidence are seen in the North (15\% in Parsees) as compared to South India ( $1 \%$ to $2 \%$ ), except in tribals of Tamil Nadu and Andhra Pradesh $(5 \%$ to $13 \%) .{ }^{4}$ In a study in Punjab, India, the incidence of G6PD deficiency in newborns was $3.9 \%{ }^{13} \mathrm{R}$ 
Iranpour et al in a similar study in an Iranian population found an incidence of $7.5 \%{ }^{14}$ Mohammad Hussain, Md. Irshad et al found a higher incidence of $13.63 \%$ in a study done in Peshawar, Pakistan. ${ }^{15}$ A similar study conducted in the United States reported a prevalence rate of $10 \%-14 \%$ among the black Americans. ${ }^{16}$ In Nigeria up to $40 \%$ of neonates with neonatal jaundice had G6PD deficiency, which implies a high prevalence rate in that region. ${ }^{17}$

The population in the States of North East is of different races, tribes and ethnic background. The prevalence of G6PD deficiency varies among the different states. The prevalence has been found to be highest $(27 \%)$ in the Angami Nagas of Nagaland (Seth and Seth 1990). ${ }^{18}$ The prevalence in Assam as found by Bhasin in 2006 is $8.8 \% .{ }^{19}$ A study conducted in Manipur in 2010 by Achoubi among the different communities found high prevalence among the Manipuri Muslims (21.32\%) followed by the Brahmins (9.45\%) and Kabui (7.84\%). ${ }^{20}$ In Mizoram also, a high prevalence of $17.5 \%$ was found in the population. ${ }^{21}$

In this study, it has been seen that among the tea garden labourers 7.6\% of them had G6PD deficiency. Balgir and Dutta in a study in 1990 found a prevalence of $6.3 \%$ among the tea garden labourers of Assam; $9.8 \%$ of the tribal population had deficiency of this enzyme in our study. The tribes mainly consisted of the Sonowal -Kacharis, Mikirs, Deuris and Rabhas. Bhatia et al in 1987 found high prevalence among the Rabhas (15.8\%) and Mikirs (15.6\%) of Assam.

Significant difference $(\mathrm{p}=.001)$ has been found in the incidence of G6PD deficiency in males (68.4\%) and females (31.5\%), which is consistent with the findings of other studies. R Iranpour found a male-to-female ratio of 3:1 (75.5\% males and $24.5 \%$ females). ${ }^{14}$ In the study done in Iran by Ezzat Khodashenas et al in the G6PD deficient group, $81.25 \%$ were males and $18.75 \%$ were females. 22 Helen E Chime et al in Nigeria also found a significant male preponderance $(35.3 \%)$ over female $(16.4 \%)$ among cases in whom deficiency of G6PD enzyme was the cause of jaundice. ${ }^{23}$

Majority of the neonates with G6PD deficiency in our study presented with neonatal jaundice between $2^{\text {nd }}$ and $4^{\text {th }}$ day of life. Other studies conducted also have found similar results. ${ }^{13,15}$

Mean peak TSB level in G6PD deficient neonates $(20.03 \pm 5.30 \mathrm{mg} / \mathrm{dL})$ is significantly higher $(\mathrm{p}<0.001)$ than G6PD normal neonates $(16.67 \pm 3.93 \mathrm{mg} / \mathrm{dL})$. In babies with significant hyperbilirubinemia, it is seen that there is significant difference $(\mathrm{p}<0.001)$ between G6PD deficient and G6PD normal babies. In 45.5\% of G6PD deficient babies, there was significant hyperbilirubinemia. Verma M, Singla D et al found that $48.7 \%$ of G6PD deficient newborns developed significant hyperbilirubinemia. ${ }^{12}$ In Riadh, Saudi Arabia, Significant hyperbilirubinemia in G6PD deficient newborns and non-deficient control group were $34 \%$ and $9 \%$ respectively $(\mathrm{p}<0.005) .^{24}$

Regarding duration of phototherapy in G6PD normal NNJ babies, majority of them $(74.1 \%)$ received phototherapy for less than 48 hours. But G6PD deficient babies received phototherapy for a longer duration; $40.25 \%$ of G6PD deficient babies received phototherapy for 3-5 days as compared to $24.4 \%$ in G6PD normal group $(\mathrm{p}<0.05)$. The requirement of phototherapy beyond 5 days is also more for G6PD deficient babies (5.1\% Vs $1.39 \%)$ than G6PD normal babies. The mean duration of phototherapy in G6PD deficient NNJ babies is
$2.5 \pm 1.2$ days, which is significantly higher $(\mathrm{p}<0.05)$ when compared to G6PD normal NNJ babies where it is $2 \pm 1.1$ days. Other similar studies have found comparable results. ${ }^{25,26}$ Mritunjay Pao et al found that the mean duration of phototherapy in the G6PD deficient neonates and neonates with normal G6Pd levels was $3.8 \pm 1.3$ days and $2.3 \pm 1.6$ days respectively $(\mathrm{p}<0.001) .25$

$45.45 \%$ of G6PD deficient babies required exchange transfusion. On the other hand, only $13.3 \%$ of G6PD normal babies required exchange transfusion. So, there is significant difference $(p<0.001)$ in requirement of DVET in the two groups. This fact is supported by the study of R Iranpour et al where exchange transfusion was needed in 50.9\%.14

All the above facts simply demonstrate that G6PD is more common in male and its deficiency causes a severe jaundice in the newborns of our region.

Although, there are few studies on prevalence of G6PD in North East India, but still there are limited studies especially in Assam, on the occurrence of neonatal jaundice and its consequences in the G6PD deficient neonates.

\section{Limitations of the Study}

Being a hospital based study done only in jaundiced patients requiring phototherapy, it does not reflect the prevalence of G6PD deficiency in the entire population of Assam. Also, it could not give the information as to how many newborns with G6PD deficiency developed jaundice, as screening of all newborns are not done in our hospital. As it is a retrospective study, future neurological outcome of the babies with significant hyperbilirubinemia requiring DVET could not be assessed.

\section{CONCLUSION}

G6PD deficiency has been found to be a common cause of neonatal jaundice. This deficiency can cause significant hyperbilirubinemia, which might lead to requirement of exchange transfusion and kernicterus if not diagnosed early or treated promptly. G6PD deficiency detection by neonatal screening is feasible and cost-effective.

So early screening is warranted to decrease the rate of exchange transfusion in the neonatal life and to take preventive measures in later life. Some practical guidance regarding the food items, herbs, chemicals and drugs to be avoided will be beneficial.

\section{ACKNOWLEDGEMENT}

The authors are particularly grateful to the staff of SCNU, Assam Medical College and Hospital for maintaining the records.

\section{REFERENCES}

1. Satish Mishra, Ramesh Agarwal, Rajiv Aggarwal, et al. Jaundice in newborn, AIIMS NICU protocol. The Indian Journal of Paediatrics 2008;75(2):57-73.

2. WHO working group. Glucose-6-phosphat dehydrogenase deficiency. Bull WHO 1989;67(6):60111.

3. Paul Schick, Francisco Talavera, Marcel E Conrad. Glucose-6-phosphate dehydrogenase (G6PD) deficiency. cited March 15, 2016. Available from Medscape: www.emedicine.medscape.com/article/200390overview. 
4. Dipika Mohanty, Malay B Mukherjee, Roshan B Colah. Glucose-6-phosphate dehydrogenase deficiency in India. Indian Journal of Paediatrics 2004;71(6):525-9.

5. Beulter E. G6PD deficiency. Blood 1994;84(11):3613-36.

6. Slusher TM, Vreman HJ, Mclaren DW, et al. Glucose-6phosphate dehydrogenase deficiency and carboxyhaemoglobin concentrations associated with bilirubin related morbiditu and death in Nigerian infants. J Pediatr 1995;126(1):102-8.

7. Brown WR, Boon WH. Hyperbilirubinemia and kernicterus in glucose-6-phosphate dehydrogenase deficient infants in Singapore. Paediatrics 1968;41(6):1055.

8. Gibbs WN, Gray R, Lowry M. G6PD deficiency and neonatal jaundice in Jamaica. $\mathrm{Br} \mathrm{J}$ Haematol 1979;43(2):263-74.

9. Baxi AJ, Balakrishnan V, Undevia JV, et al. Glucose-6phosphate deficiency in the parsee community, Bombay. Indian Journal of Medical Sciences 1963;17(6):493-500.

10. Naik SN. Glucose-6-phosphate dehydrogense deficiencyin India and its clinical significance. The Journal of Association of Physicians of India 1994;42(3):229-34.

11. Narayan R. A study of pattern of admission and outcome in a neonatal intensive care unit at high altitude. Sri Lanka Journal of Child Health 2012;41(2):79-81.

12. Anwar Zeb Jan, Samreen Ahmad, Shahzada Baktyar Zahid. Clinical audit of admission and its outcome in a neonatal ICU. Glomal Journal of Medical Sciences 2013;11(1):31-6.

13. Verma M, Singla D, Crawell SB. G6PD deficiency in neonates: a prospective study. Indian J Paediatr 1990;57(3):385-8.

14. Iranpour R, Akbar MR, Haghshenas I. Glucose-6phosphate dhydrogenase deficiency in neonates. Indian Journal of Paediatrics 2003;70:855-7.

15. Mohammad Hussain, Mohammad Irshad, Musa Kalim, et al. Glucose-6-phosphate dehydrogenase deficiency in jaundiced neonates. JPMI 2010;24(2):122-6.

16. Washington EC, Ector W, Abboud M, et al. Haemolytic jaundice due to G6PD deficiency causing kernicterus in a female newborn. South Med J 1995;88(7):776-9.
17. Ahmed H, Yukuba AM, Hendrickse RG. Neonatal jaundice in Zaria, Nigeria-a second prospective study. West Afr J Med 1995;14(1):15-23.

18. Seth PK, Seth S. Biogenetical studies of nagas: glucose-6phosphate dehydrogenase deficiency in Angami Nagas. Human Biology 1971;43(4):557-61.

19. Bhasin MK. Genetics of castes and tribes of India: glucose-6-phosphate dehydrogenase deficiency and abnormal haemoglobins (HbS and HbE). Int J of Human Genetics 2006;6(1):49-72.

20. Achoubi N, Mohd Asghar, Meiti SY, et al. Haemoglobinopathies and glucose-6-phosphate deficiency in a malaria endemic region of Manipur, Northeast India. Anthropological Science 2010;118(3):201-4.

21. Dash S, Chhanhimi L, Zomawaia E. Screening for haemoglobinopathies and glucose-6-phosphate deficiency among mizos of mizoram: a preliminary study. Indian Journal of Pathology and Microbiology 2005;48(1):17-8.

22. Ezzat Khodashena, Faenaz Kalani-Moghaddam. G6PD deficiency and neonatal hyperbilirubinemia. Iranian Journal of Neonates 2015;6(3):28-31.

23. Helen E Chime, Joseph A Egende, John E Arute. Prevalence of neonatal jaundice on central hospital, Warri, delta state, Nigeria. International Journal of Health Research 2011;4(3):123-6.

24. Yaish HM, Niazi GA, Al-Shaalan $M$, et al. Increasing incidence of hyperbilirubinemia in "unchallenged" glucose-6-phosphate dehydrogenase deficiency in term Saudi newborns. Ann Trop Paediatr 1991;11(3):259-66.

25. Mritunjay Pao, Anjali Kulkarni. Neonatal screening of glucose-6-phosphate deficiency. Indian Journal of Paediatrics 2005;72:835-7.

26. Manik Mondal, Asok Kumar Datta, Syamali Mandal, et al. Study of glucose-6-phosphate dehydrogenase in neonatal jaundice. Journal of Pharmacy and Biological Sciences 2012;1(5):30-6. 